\title{
FlexDanmark Optimizes Scandinavian Software Solution to Deliver Efficient, High Quality Transportation to Its Citizens
}

By Jana Lynott

\section{In October 2018, AARP's Office of Policy, Research and International Affairs staff Jana Lynott and Kim Sedmak traveled to Denmark for a study tour and video shoot of the successful FlexDanmark transportation system.}

W hen it comes to transportation for older adults, people with disabilities, and rural residents, Denmark is known in transit circles for offering efficient and customer-satisfying service. The AARP Public Policy Institute confirmed this to be true during an eight-day study tour and video shoot of the FlexTrafik system. The entity behind the system, FlexDanmark - a nationwide software company owned by five regional public transport authorities - offers a global model for truly coordinated demand responsive transportation service.

Driving all the transit choreography are the public company's five call centers that are integrated through a central nationwide dispatch system. That system assigns each trip request to a transportation provider that then sends an appropriate vehicle to the customer's door. More than 550 unique private transportation providers are integrated into this single system, which serves both urban and rural customers throughout Denmark. Hospitals, medical offices, and human service agencies easily connect their clients using the FlexDanmark portal. Regular citizens can obtain transportation to a doctor's appointment or other destination at a more affordable price than a taxi, because FlexDanmark can quickly identify another customer to share a ride with. Trips may be booked with lead times ranging from up to two weeks to two hours before.

\section{How FlexDanmark's Services Work} FlexDanmark offers several fully integrated services within its FlexTrafik platform ${ }^{1}$ :

- A service going by the name FlexPatient provides free transportation from home to hospital for patients who cannot arrive by regular public transportation because of illness, disability, frailty, or lack of adequate transit service in rural areas. FlexPatient service is guaranteed by federal law.

- FlexHandicap, another service, is for individuals with a severe mobility impairment. Under federal law, Denmark's regional transportation authorities must provide at reduced cost 104 one-way leisure trips per year to citizens with severely reduced mobility because of disability or frailty, at an out-of-pocket cost no higher than the cost of public transportation.

- Municipalities have the option of subsidizing other services within the FlexTrafik platform:

1. Most municipalities invest in FlexTur, which allows any citizen to arrange demand responsive transportation through FlexTrafik. FlexTur riders share the cost of transportation with their sponsoring municipality.

2. About half of the municipalities invest in FlexMunicipality, subsidized transportation to get residents to non-hospital medical appointments.

What is significant about these services is that they may use the same vehicles to transport different categories of customers. For instance, our study 


\section{"More than 550 unique private transportation providers are integrated into this single system, which serves both urban and rural customers throughout Denmark."}

group followed Gitte, a FlexHandicap passenger, and Susanne, a FlexTur customer, as they shared a vehicle to arrive at their respective destinations. By opening up the service to all citizens, the regional transportation authorities are able to transport more passengers in fewer vehicles, and offer them shared, yet shorter, trips. Because the platform stores rider profiles, the system is smart enough to bill each hospital, municipality, and rider according to clear cost allocation formulas. Rider profiles also indicate whether someone needs a wheelchair accessible vehicle or additional time to board. And hospital staff requesting rides for their patients can indicate if the individual needs a private vehicle without other passengers. The information is exchanged automatically - literally within seconds of the system receiving a trip request. But a dozen call center staff per- sons are available should a problem arise or for cases when a customer prefers to request a trip by phone, rather than computer or smart phone.

\section{Cost Efficiency Mechanisms}

FlexDanmark has created economies of scale through several coordinated interventions:

- Single-source contracts with individual providers, e.g., a taxicab company, were replaced by negotiated contracts with numerous providers that could meet the company's standards for driver licensing, training, and cost. When a trip request is received, FlexDanmark can schedule that trip with any number of providers.

- The five regional transportation authorities negotiate contracts with providers in their region on behalf of all municipalities within the region. In that way, they are able to put in place a better price for service.

- The FlexDanmark system views all ride requests as a pool of rides that can be planned together without limitation. The software identifies the optimal shared ride arrangements, placing all categories of customers on the same vehicle depending on their locations of origin and destinations, as well as time of travel, traffic conditions, and specific traveler needs (e.g., wheelchair accessible vehicle, assistance getting in/out of the vehicle, etc). Furthermore, because each of the regional FlexDanmark operation centers are part of the larger national system, geographic boundaries do not pose a barrier.

- To keep FlexTur trip requests from skyrocketing and competing with regular public transportation service, municipalities and regional transportation authorities often set the FlexTur demand responsive trip price at a level high enough to encourage use of regular buses and trains. Outside urban areas, where fixed route public transportation service is not an option, the out-of pocket costs for FlexTur riders are comparable to that of regular public transportation. 


\section{LIVABLE COMMUNITIES}
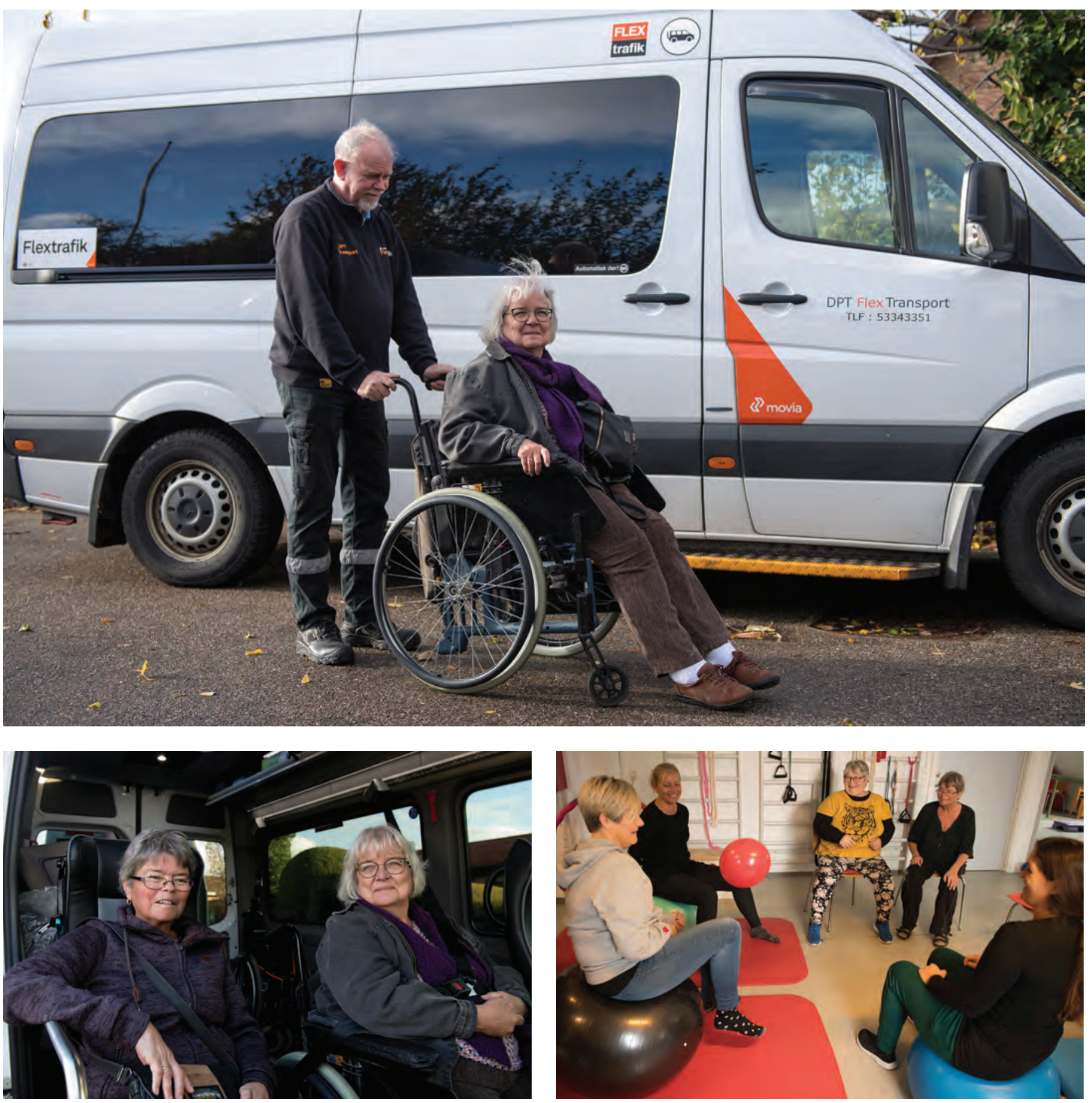

TOP “Loneliness kills you," says Gitte

Aakjaer, a FlexHandicap customer who uses a wheelchair. "Flextrafik is the best way to have a social life. Because they can drive you anywhere." воттом Left Today, Susanne and Gitte share a ride on a FlexTrafik vehicle to their respective appointments.

вотTOм RIGHT Susanne takes the bus to her fitness class. As a FlexTur customer Suzanne shares the cost of the transportation service with her municipality. She finds FlexTrafik's curb-to-curb service more convenient than the regular bus, but less expensive than a private taxi. 
Photos by Mirjam Evers

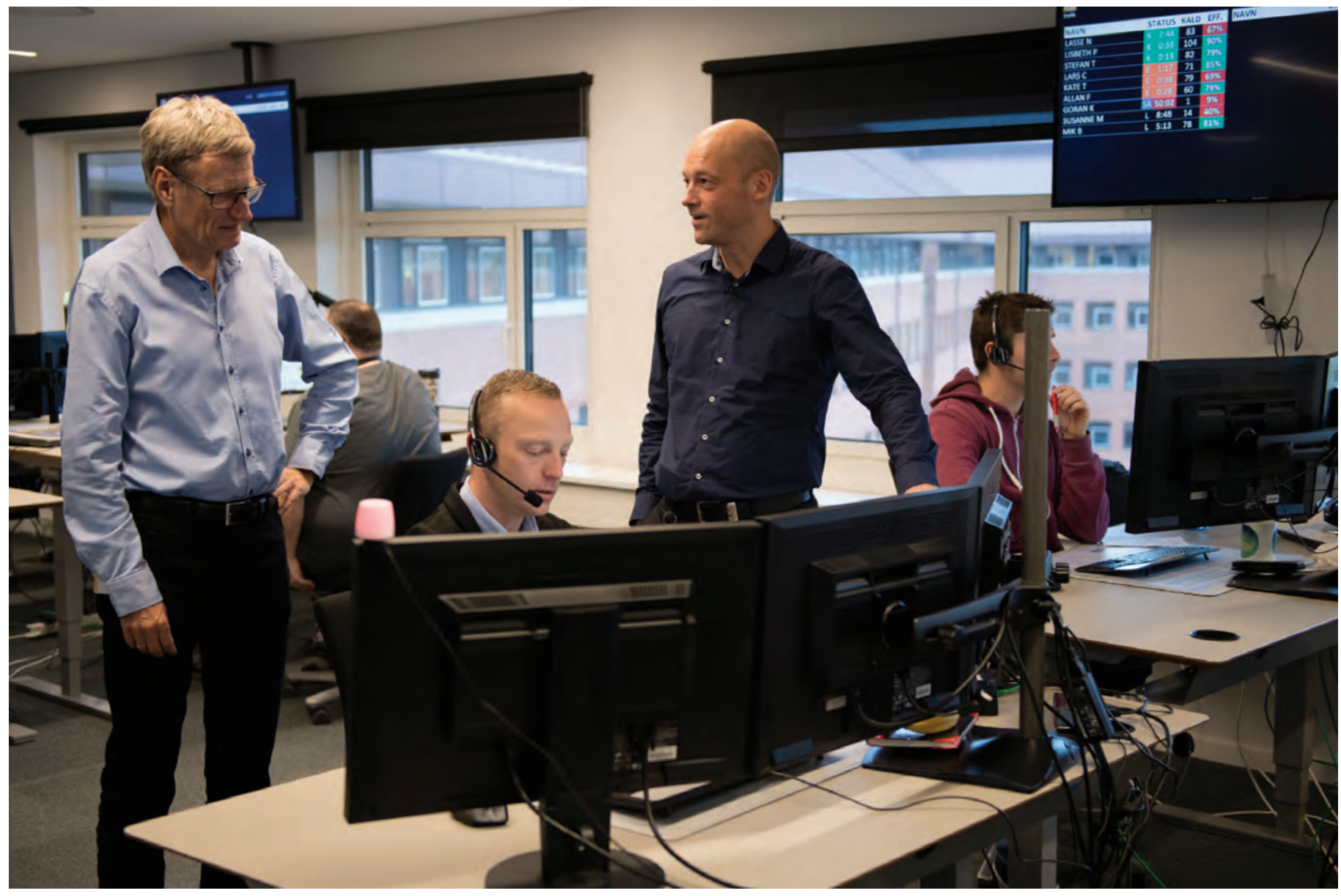

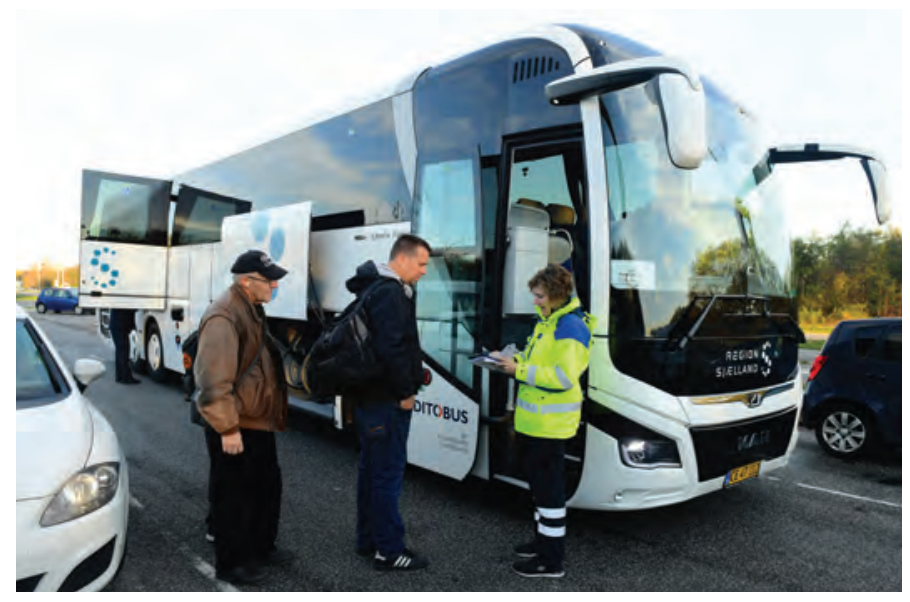

TOP FlexTrafik's technology masterminds converse with staff in the command center. The status of trips is tracked on wall monitors. 115 FlexDanmark employees ensure the buses run smoothly, payors are properly billed, and services are coordinated with larger regional transportation operations.

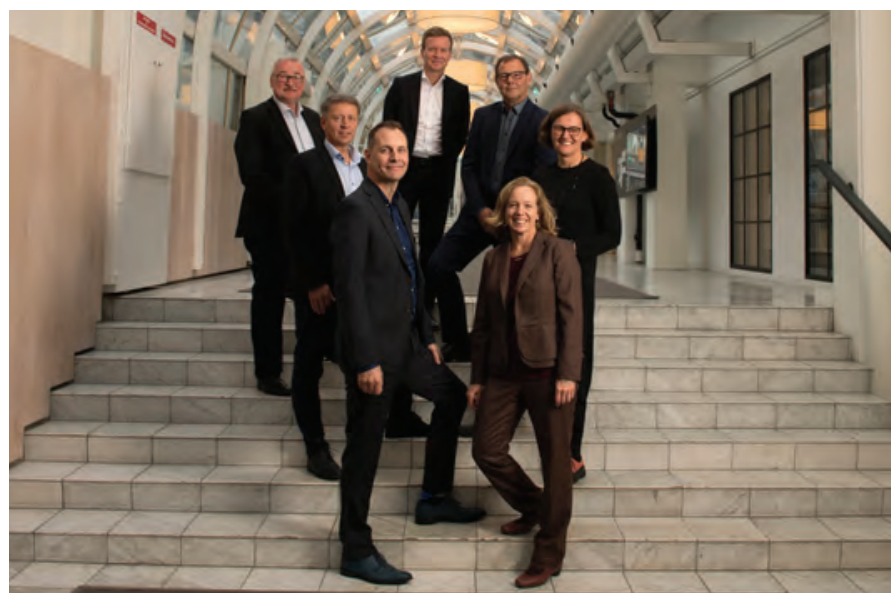

ABOVE LEFT FlexMedical passengers transferring to the larger regional Medical bus.

ABOVE RIGHT The author poses with FlexDanmark Transportation Authority CEOs. 


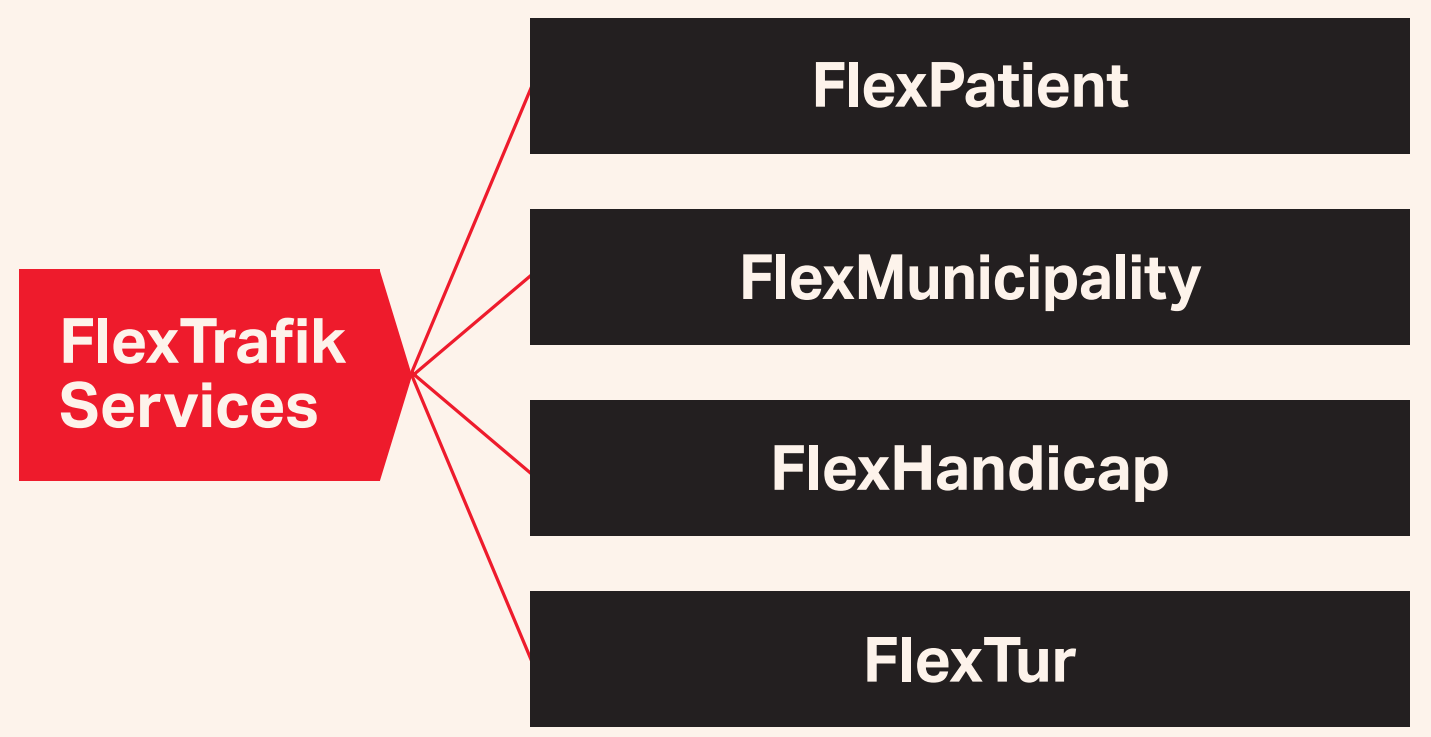

The result of these measures has been more competition within the system, higher vehicle utilization rates (aka, more ridesharing), lower trips costs, and more timely service.

The sophisticated level of coordination is possible because all providers in the system adopted a common transactional data specification. In other words, they all use a standardized approach to exchange trip data similar to that used by online travel agencies like Expedia. Originally developed in Sweden, the SUTI (Standardiserat Utbyte av Trafik Information) specification standardizes trip request data across multiple providers and platforms. A huge volume of exchangeable data is generated and managed by software applications that are SUTI-compliant, enabling as many as 16,000 trips daily to be booked and completed in Denmark.
The specification has lowered the market-entry costs for new (often small) transportation business owners and has reduced the cost of providing human services transportation on average by 20 percent, and as much as 40 percent for rural trips. This cost savings is beneficial to customers who pay out of pocket for the service, as well as the hospitals and municipalities that subsidize travel.

Denmark's system was not always so efficient. Prior to the establishment of FlexDanmark, transport authorities carried out their federal mandate to provide medical transportation to all qualifying citizens by arranging transportation for clients in private taxis. While the cost of transportation was just a fraction of the total spending on health care and other services, on the aggregate, by itself the transportation subsidy was still huge, motivating regional transportation authorities to discover a more efficient means of delivering the service, thus paving the way for the creation of FlexDanmark.

In many respects, the preFlexDanmark medical transportation system resembled that of Medicaid Non- Emergency Medical Transportation (NEMT) in the US today (Note: Medicaid NEMT is the only federally mandated transportation service in the US not limited by geography. It is for very low-income qualifying individuals, and only for medical trip purposes). Only 0.40 percent (4/10ths of 1 percent) of the federal Medicaid budget goes to transportation; however, that translates into $\$ 1.5$ billion in annual spending - the largest human services transportation outlay of any federal agency, even that by the Department of Transportation. 


\section{"By opening up the service to all citizens, the regional transportation authorities are able to transport more passengers in fewer vehicles, and offer them shared, yet shorter, trips."}

As a result, numerous states, which are responsible for cost-sharing, are looking at ways to lower their transportation costs. Some have put in place transportation brokers that tap multiple providers in the community. But none employs the underlying specification that facilitates efficient, automated discovery of available vehicles, trip scheduling, and payment among numerous independent transportation operators.

That could change. This year, the National Academies of Science in the US, developed a common transactional data specification for demand responsive transportation modeled on that in use in Denmark and other Scandinavian countries. AARP will be among those advocating for its widespread adoption.

\section{Accessible Transit = Quality of Life = Better Health}

AARP's Public Policy Institute and other research organizations have documented the health and society costs of social isolation. An important theme that kept resurfacing during the study tour was the importance of the FlexDanmark transportation service for health - not only to get patients to health care appointments, but also to allow everyone in the community the opportunity to engage socially. As mentioned above, Danish law guarantees transportation for one leisure outing each week for individuals with a certified disability. Other residents may pay more but also access the service. As FlexTur rider Susanne Riis eloquently stated in her secondlanguage English:

"Flextur is making me healthier because I can get around. I can meet other people. I'm not getting lonesome. I think my health will be [worse] if I was just sitting in the mobile home or in my house all day without coming out. If I have not been using Flextur, I think I would have a very boring life. Especially now when I cannot see. It's important for me to go out and meet other people." •

1. Danish names of the services are provided in parentheses. FlexPatient (Patientbefordring), FlexHandicap (Handicapkørsel), FlexTur (Flextur), FlexMunicipality (Kommunale kørselsordninger)

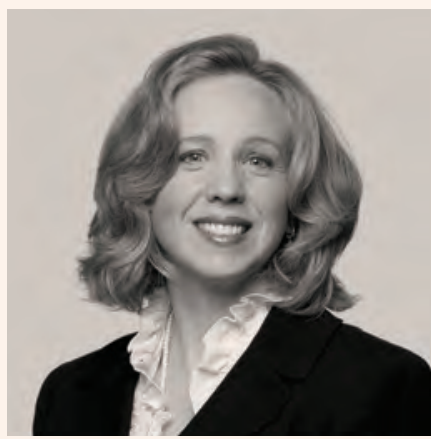

Jana Lynott SENIOR STRATEGIC POLICY ADVISOR, PUBLIC POLICY INSTITUTE, AARP 